\title{
Descrição do girino de Lysapsus laevis (Parker), com notas sobre o ambiente, hábitos e desenvolvimento (Anura, Hylidae, Pseudinae)
}

\author{
Ulisses Caramaschi ${ }^{1,2} \&$ Helianne de Niemeyer ${ }^{1}$ \\ ${ }^{1}$ Departamento de Vertebrados, Museu Nacional, Universidade Federal do Rio de Janeiro. Quinta da Boa Vista, São \\ Cristóvão, 20940-040 Rio de Janeiro, Rio de Janeiro, Brasil. \\ 2 Bolsista CNPq. E-mail: ulisses@acd.ufrj.br
}

\begin{abstract}
Description of the tadpole of Lysapsus laevis (Parker), with notes on the habitat, habits, and development (Anura, Hylidae, Pseudinae). The tadpole of Lysapsus laevis (Parker, 1935) is described and figured, based on specimens from Vila Surumu, State of Roraima, northern Brazil. In stage 37, the tadpole attains $61.4 \mathrm{~mm}$ in total length; body triangular in lateral view, ovoid in dorsal and ventral views, corresponding to $28 \%$ of the total length; eyes lateral, partially visible in dorsal and ventral views; oral disc anteroventral, small; labial tooth row formula, 2(2)/3(1); spiracle short, sinistral; anal tube large, wide, medium; in life, dorsum of body green, venter iridescent white; caudal musculature and fins green; anterior third of caudal fin and anal tube with irregular iridescent stains; distal half of tail gray to dark gray; iris bronze. Notes on the habitat, habits, and development are provided.
\end{abstract}

KEY WORDS. Lavrados, Roraima, tadpole.

RESUMO. O girino de Lysapsus laevis (Parker, 1935) é descrito e figurado, com base em exemplares coletados na Vila Surumu, Estado de Roraima, Brasil. No estágio 37, o girino possui $61,4 \mathrm{~mm}$ de comprimento total; corpo triangular em vista lateral, ovóide em vistas dorsal e ventral, correspondendo a $28 \%$ do comprimento total; olhos laterais, parcialmente visíveis em vistas dorsal e ventral; disco oral ânteroventral, pequeno; fórmula dentária, 2(2)/3(1); espiráculo curto, sinistro; tubo anal longo, largo, direito, mediano; em vida, dorso do corpo verde, ventre branco iridescente; musculatura caudal e nadadeiras verdes; terço anterior da nadadeira caudal e tubo anal com manchas irregulares iridescentes; metade distal da cauda cinza a cinza escuro; íris bronze. Notas sobre o ambiente, hábitos e desenvolvimento são apresentadas.

PALAVRAS CHAVE. Lavrados, Roraima.

O gênero Lysapsus Cope, 1862 (Anura, Hylidae, Pseudinae) atualmente contém três espécies, $L$. limellus Cope, 1862, L. laevis (Parker, 1935) e L. caraya Gallardo, 1964 (KLAPpenbaCH 1985, Frost 2002). Destas, apenas L. limellus teve o girino descrito, com base em exemplares provenientes de $5 \mathrm{~km} \mathrm{~S}$ Paso de la Patria, Provincia de Corrientes, Argentina (KeHr \& Basso 1990).

Neste trabalho, o girino de Lysapsus laevis é descrito e figurado, e são apresentadas observações sobre seu ambiente, hábitos e desenvolvimento.

\section{MATERIAL E MÉTODOS}

Girinos de Lysapsus laevis em vários estágios de desenvolvimento foram coletados em poça de água semi-permanente $\left(04^{\circ} 12^{\prime} \mathrm{N}, 60^{\circ} 49^{\prime} \mathrm{W}\right)$, à margem direita da estrada para a Vila Surumu, Município de Pacaraima, Estado de Roraima, Brasil, em 26.X.1998, por U. Caramaschi, H. de Niemeyer e D. F. de Moraes Jr. Os girinos foram fixados em formalina a 5\% logo após a coleta e atualmente encontram-se depositados na coleção do Museu Nacional, Rio de Janeiro (MNRJ), constituindo lote de 242 exemplares distribuídos entre os estágios 25 a 46 . Essa variedade de estágios, incluindo jovens recém-metamorfoseados, e a presença abundante de adultos no ambiente possibilitou a associação entre estes e as larvas e a correta identificação da espécie.

A determinação dos estágios de desenvolvimento larvário foi feita segundo Gosner (1960). A fórmula dentária segue Altig (1970). As medidas, realizadas com paquímetro digital sob microscópio estereoscópico, seguem Altig \& McDiarmid (1999), exceto a distância internasal e a distância interorbital, que foram medidas, respectivamente, entre as bordas internas das narinas e dos olhos.

Revista Brasileira de Zoologia 21 (3): 449-452, setembro 2004 


\section{RESULTADOS \\ Lysapsus laevis (Cope, 1935)}

Figs 1-4

Girino (MNRJ 27264). Estágio 37. Medidas (mm): comprimento total 61,4 ; comprimento do corpo 17,2; altura do corpo 15,0; largura do corpo 11,5; comprimento da cauda 44,2; altura da cauda 12,8; altura da nadadeira dorsal 5,8; altura da nadadeira ventral 6,6; altura da musculatura da cauda 4,6 ; distância focinho-narina 2,5; distância internasal 2,9; distância narina-olho 3,5; diâmetro do olho 2,3; distância interorbital 7,3; largura da boca 2,8; comprimento do espiráculo 2,8; comprimento do tubo anal 8,0. Corpo triangular em vista lateral (Fig. 1), ovóide em vista dorsal ou ventral (Figs 2-3), correspondendo a $28 \%$ do comprimento total; altura máxima do corpo no seu terço médio; focinho ligeiramente acuminado em vista lateral, arredondado em vista dorsal; olhos laterais, pouco acima da linha média do corpo, parcialmente visíveis tanto em vista dorsal como ventral; narinas ovaladas, dorsais, colocadas em pequenas depressões, pouco mais próximas da ponta do focinho que do olho; distância internasal menor que a distância narina-olho e maior que o diâmetro do olho; espaço interorbital amplo, pouco mais de três vezes o diâmetro do olho; espiráculo único, curto, sinistro, localizado ligeiramente abaixo da linha média, no início do terço médio do corpo; espiráculo com parede interna livre do corpo, abertura voltada para trás e para cima; tubo anal longo, largo, mediano com ambas as paredes ligadas diretamente à nadadeira ventral; nadadeira dorsal com origem no final do terço anterior do corpo, à altura dos olhos, de contorno ascendente até o terço anterior da cauda e descendente até seu final; extremidade da cauda estreita, arredondada, sem formar flagelo; nadadeira ventral levemente arqueada; altura máxima da cauda no seu terço anterior; disco oral ântero-ventral, pequeno, aproximadamente elíptico, não emarginado (Fig. 4); fórmula dentária, 2(2)/3(1); parte superior do bico córneo longa, relativamente estreita, plana e serrilhada na região central, e arqueada, finamente serrilhada, nas extremidades; parte inferior em forma de " $V$ " aberto, serrilhada em toda a extensão; papilas labiais presentes em quase toda a extensão do disco oral, ausentes apenas na porção mediana do lábio superior; papilas uniseriais nos lábios superior e inferior, biseriais a multiseriais nas laterais.

Colorido. Em vida, dorso do corpo verde; ventre branco iridescente; nadadeiras e musculatura caudal verdes; terço anterior da nadadeira ventral e tubo anal com manchas iridescentes irregulares, sem formar desenho definido; metade distal da cauda cinza a cinza escuro; íris bronze. Em preservativo, o colorido geral torna-se cinzento, nitidamente mais escuro na metade distal da cauda; desaparecem as iridescências e as espirais intestinais, relativamente amplas, tornam-se visíveis por transparência da pele.

Ambiente e hábitos. A região estudada, situada no nor- deste do Estado de Roraima, Brasil, foi detalhadamente analisada quanto ao relevo, vegetação, drenagem e clima por Vanzolini \& Carvalho (1991) e em Barbosa et al. (1997). Com aproximadamente $35.000 \mathrm{~km}^{2}$ de área, essa região é coberta por formações abertas, chamadas "lavrados". Esses campos estão restritos à metade norte de uma das maiores unidades morfoestruturais de Roraima, chamada de Pediplano Rio Branco-Rio Negro. A superfície topográfica dos lavrados é relativamente plana, com cerca de 80 a $160 \mathrm{~m}$ de altitude. Essa paisagem plana, mas que também apresenta "inselbergs" graníticos, gnáissicos e migmatíticos, está em estágios iniciais de dissecação pela drenagem. Esta é caracteristicamente dendrítica, com riachos se originando em brejos de baixada, geralmente formando veredas.

Estruturalmente, os lavrados são formações abertas, com três estratos de vegetação. O estrato inferior é composto por gramíneas (Poaceae), com grande predominância de capins dos gêneros Andropogon e Trachypogon. O estrato médio é composto por arbustos esparsos eretos ou recumbentes e o estrato superior é formado por árvores baixas, usualmente bastante dispersas, mas formando agregados quando presentes. O estrato arbóreo pode ser tão rarefeito que se torna praticamente ausente; por outro lado, as árvores podem aparecer reunidas em capões de perímetro arredondado. A "lixeira" ou "caimbé", Curatella americana, é a espécie arbórea predominante nos lavrados, o que reforça a semelhança fisionômica desta formação com os cerrados do Brasil Central.

O total de precipitação anual gira em torno de $2000 \mathrm{~mm}$, com uma estação mais seca entre outubro e março e outra úmida, entre abril e agosto, sendo junho o mês mais chuvoso. A temperatura é sempre alta, com pequena amplitude térmica durante o ano, entre cerca de 26 e $30^{\circ} \mathrm{C}$. Os meses menos quentes coincidem com os meses mais chuvosos.

A coleta dos girinos e adultos de Lysapsus laevis foi realizada na região dos lavrados. O solo argiloso e pouco permeável possibilita acúmulo de água de chuvas e de transbordamento de rios, formando poças semi-permanentes. Girinos foram obtidos em uma dessas poças, que media aproximadamente $50 \mathrm{~m}$ de comprimento, $15 \mathrm{~m}$ de largura e máximo de $1 \mathrm{~m}$ de profundidade, mas foram também observados em outras poças de tamanhos diversos. A água era sempre limpa e transparente, com vegetação emergente composta basicamente por juncáceas e vegetação flutuante constituída principalmente por ninfeáceas. Os girinos nadam a meia água, sem formar cardumes, tendo atividade predominantemente diurna. Nas mesmas poças foram também obtidos girinos de Pseudis paradoxa (Linnaeus, 1758) (Hylidae, Pseudinae) e de Hyla sp. (Hylidae, Hylinae).

Desenvolvimento. A presença simultânea de girinos nos mais diversos estágios de desenvolvimento (estágios 25 a 46) na mesma poça revela que ocorreram muitas desovas sucessivas e temporalmente superpostas. Além disso, pelo ambiente caracterizar-se como semi-permanente, aparentemente não ocorreram estímulos para aceleração do desenvolvimento, pelo 

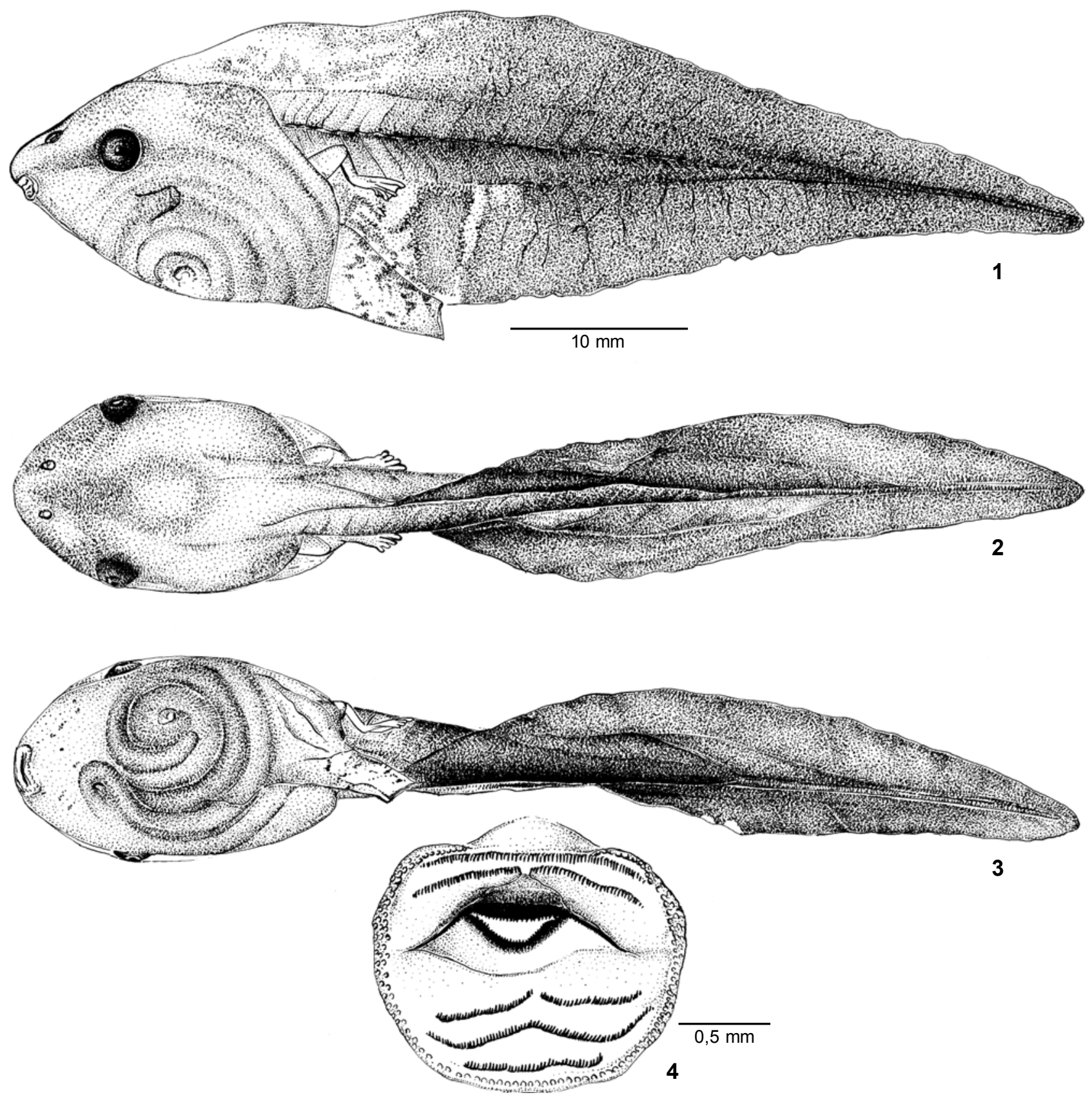

Figuras 1-4. Girino de Lysapsus laevis (MNRJ 27264; estágio 37): (1) vista lateral; (2) vista dorsal; (3) vista ventral; (4) disco oral.

que os girinos apresentam grande crescimento corporal sem haver mudança de estágio (e.g., girinos no estágio 25 possuem comprimento total entre 14,8 a $40,3 \mathrm{~mm}$ ). O maior comprimento total $(66,4 \mathrm{~mm})$ ocorreu em girino no estágio 37 . A partir deste, há lenta regressão até o estágio 42 , que atinge $60,4 \mathrm{~mm}$ de comprimento total. Logo após a liberação dos membros anteriores, a partir do estágio 43 , no qual o girino possui 54,6$54,8 \mathrm{~mm}$ de comprimento total, ocorre rápida absorção da cauda, com conseqüente diminuição abrupta do comprimento total para 33,2-36,5 $\mathrm{mm}$ no estágio 44 , depois $15,7-25,5 \mathrm{~mm}$ no estágio 45 e finalmente jovens recém-metamorfoseados (estágio 46) com 13,5-16,5 mm de comprimento rostro-cloacal. 
O tamanho do jovem recém-metamorfoseado é muito próximo do comprimento rostro-cloacal dos adultos (amplitude 16,4-21,2 mm; $x=19,1 \mathrm{~mm} ; \mathrm{DP}=1,52 ; \mathrm{n}=10$ machos). Essa característica é expressiva de espécie que se reproduz em ambiente estável, com grande permanência, na qual o crescimento principal ocorre na fase larvária, em oposição àquelas espécies de reprodução em ambientes instáveis, efêmeros, cujo desenvolvimento é rápido e o jovem recém-metamorfoseado mostra-se acentuadamente menor que o adulto, de maneira que o crescimento principal se dá após a metamorfose.

\section{DISCUSSÃO}

O girino de Lysapus laevis se distingue prontamente do girino de L. limellus, descrito por KeHr \& Basso (1990), pelo tamanho maior $(60,7-66,4 \mathrm{~mm}$ de comprimento total em girinos de L. laevis no estágio 37; 33,7-37,0 mm nos girinos de L. limellus no mesmo estágio), pela fórmula oral [2(2)/3(1) em L. laevis; 2(2)/3 em L. limellus], pelo menor número de fileiras de papilas labiais (uniseriais nos lábios anterior e posterior, biseriais a multiseriais nas laterais em L. laevis; duas fileiras nas regiões laterais e posterior dos lábios em L. limellus) e colorido (L. laevis apresenta a metade distal da cauda cinza a cinza escuro; L. limellus possui a extremidade caudal nitidamente preta).

A fisionomia do ambiente ocupado por L. laevis é essencialmente a mesma daquele ocupado por L. limellus, descrito por KeHR \& BASso (1990) como uma poça semi-permanente em área sub-tropical (tropical para L. laevis), com cerca de $10 \mathrm{~m}$ de largura, $60 \mathrm{~m}$ de comprimento e $1 \mathrm{~m}$ de profundidade; abrigava grande quantidade de insetos aquáticos predadores (hemípteros belostomatídeos, notonectídeos e naucorídeos e odonatas gonfídeos), mas sem presença de peixes; os girinos ocorriam a meia água, entre a densa vegetação aquática. KeHr \& BASso (1990) argumentam que a extremidade preta da cauda do girino de $L$. limellus poderia servir para defletir o ataque de certos predadores, como sugerido por CALdwell $(1982,1986)$ para algumas espécies de hilídeos norte-americanos. Apesar de ocorrerem muitos predadores potenciais nos ambientes de L. laevis (insetos aquáticos e peixes caracídeos), não houve evidência de que a cauda cinza dos girinos constituísse algum mecanismo antipredação, mas essa possibilidade não pode ser descartada.

As diferenças morfológicas e de colorido observadas entre os girinos de L laevis e $L$. limellus demonstram que a fase larvária constitui bom elemento de distinção entre as espécies do gênero. Atualmente, L. laevis é a única delas a conter duas subespécies (L. l. laevis e L. l. bolivianus Gallardo, 1961; KLAPPENBACH 1985, Frost 2002), sendo o presente estudo referente à subespécie nominal. Assim sendo, o estudo das larvas das duas subespécies de L. laevis pode constituir passo fundamental para a reavaliação de suas posições taxonômicas e eventual reconhecimento de ambas como espécies plenas.

\section{AGRADECIMENTOS}

A Décio Ferreira de Moraes Jr. pelo auxílio nos trabalhos de campo e companheirismo; a Luiz Flamarion Barbosa de Oliveira pela oportunidade da viagem ao campo; a Sebastião Pereira do Nascimento e Reinaldo Imbrozio Barbosa pela assistência em Boa Vista (RR); a Francisco Roberto pelas facilidades de acomodação na Vila Surumu (RR); a Paulo Roberto Nascimento pelos desenhos a nanquim; a Henrique Wogel pela leitura crítica do manuscrito. Ao Conselho Nacional de Desenvolvimento Científico e Tecnológico (CNPq) e à Fundação Carlos Chagas Filho de Amparo à Pesquisa do Estado do Rio de Janeiro (FAPERJ), pelo apoio financeiro.

\section{REFERÊNCIAS BIBLIOGRÁFICAS}

Altig, R. 1970. A key to the tadpoles of the continental United States and Canada. Herpetologica, Lawrence, 26 (2): 180207.

Altig, R. \& R.W. McDiarmid. 1999. Body plan. Development and morphology, p. 24-51. In: R.W. McDiarmid \& R. Altig (Eds). Tadpoles. The Biology of Anuran Larvae. Chicago, The University of Chicago Press. XVI+444p.

Barbosa, R.I.; E.J.G. Ferreira \& E.G. Castellón. 1997. Homem, Ambiente e Ecologia no Estado de Roraima. Manaus, Instituto Nacional de Pesquisas da Amazônia, XVI+613p.

CALDWELl, J.P. 1982. Disruptive selection: a tail color polymorphism an Acris tadpoles in response to differential predation. Canadian Journal of Zoology, Ottawa, 60: 2818-2827.

- 1986. A description of the tadpole of Hyla smithii with comments on tail coloration. Copeia, Lawrence, 1986 (4): 1004-1006.

Frost, D.R. 2002. Amphibian species of the world: an online reference. V2.21 (15 July 2002). Disponível: http://research. amnh.org/herpetology/amphibia/index.html.

GosNER, K.L. 1960. A simplified table for staging anuran embryos and larvae with notes on identification. Herpetologica, Lawrence, 16 (2): 183-190.

Kehr, A.I. \& N.G. Basso. 1990. Description of the tadpole of Lysapsus limellus (Anura, Pseudidae) and some considerations on its biology. Copeia, Lawrence, 1990 (3): 573-575.

KlappenbaCH, M.A. 1985. Notas herpetologicas, V. Comunicaciones Zoologicas del Museo de Historia Natural de Montevideo, Montevideo, 11 (150): 1-23.

Vanzolini, P.E. \& C.M. Carvalho. 1991. Two sibling and sympatric species of Gymnophthalmus in Roraima, Brasil (Sauria, Teiidae). Papéis Avulsos de Zoologia, São Paulo, 37 (2): 173-226.

Recebido em 11.XI.2003; aceito em 22.VI.2004. 